\title{
PARA AILTON KRENAK EM A VIDA NÃO É ÚTIL, "SOMOS A PRAGA DO PLANETA", MAS PODEMOS MUDAR
}

\author{
For Ailton Krenak in A vida não é útil, "We are the plage of the planet", but change \\ is possible
}

\author{
Melina Pereira Savi \\ https://orcid.org/0000-0003-3803-1892 c \\ Universidade Federal de Santa Catarina, Programa de Pós-Graduação em Inglês, \\ Florianópolis, SC, Brasil. 88040-900 - ppgi@contato.ufsc.br
}

KRENAK, Ailton. A vida não é útil. São Paulo: Companhia das Letras, 2020.

\section{É preciso mudar}

O título do novo livro de Ailton Krenak, uma das principais vozes indígenas de resistência no Brasil na atualidade, é a tradução em miúdos da antítese do instrumentalismo que nos leva a destruir a natureza como se não houvesse amanhã: $A$ vida não é útil. Transformar tudo o que vive em instrumento passível de uso na corrida em direção ao progresso - "essa ideia prospectiva de que estamos indo para algum lugar" (KRENAK, 2020, p. 10) - é, de fato, o caminho para um lugar: o fim de nós mesmos. O revés desse "nós mesmos" é que a ideia não dá conta de exprimir o que está em jogo. Conforme Krenak, a nossa visão de humanidade é falha, pois incluímos nela apenas os seres humanos ou, pior, apenas alguns deles, pois dentro da nossa concepção de humanidade há os humanos e os sub-humanos, e na pandemia do novo coronavírus fica claro quem pertence a qual grupo. Como aponta o autor, em nome da economia, que parece ter mais importância que a vida em si, jogamos com a ideia de que "alguns vão morrer", frase de fato proferida em entrevista pelo atual presidente da república. Essa perspectiva entende a vida de uns como mais relevante que a de outros (geralmente com base em raça, em classe, em gênero, em espécie e em idade) e, nas palavras de Krenak, "afeta as pessoas que amam os idosos, que são avós, pais, filhos e irmãos” (2020, p. 85). A noção de que alguns vão, inevitavelmente, se sacrificar - voluntária e involuntariamente - em nome da saúde da economia pessoaliza uma esfera social que deveria estar a serviço dos humanos e despessoaliza ainda mais humanos que nunca conseguiram esse status ou que um dia o tiveram e perderam. 
O "afeto", que reflete tanto a noção de impacto quanto a de cuidar, com base na simpatia e no carinho, aparece na passagem supracitada e em tantas outras da referida obra de Krenak. O livro foi lançado em agosto de 2020 pela editora Companhia das Letras e conta com cinco ensaios que serão analisados, observando os pontos principais dos capítulos na ordem em que eles aparecem. $A$ vida não é útil estabelece um diálogo com outro livro do mesmo autor e editora, o Ideias para adiar o fim do mundo, publicado em 2019 , e é de certa forma uma continuação deste. No mesmo formato de Ideias para adiar o fim do mundo, com ensaios curtos adaptados de falas de Krenak, principalmente sobre o impacto das ações humanas no planeta e nas comunidades indígenas, $A$ vida não é útil aborda, além desses temas, a pandemia do novo coronavírus, e aprofunda a ideia de que o modo de vida que levamos e as pegadas que estamos deixando no planeta nos levarão à ruína. A pior notícia, como Krenak sinaliza em diversos momentos, é que levaremos (e já levamos) inúmeras espécies conosco. Já a boa notícia, se é que é possível colocar desta forma, é que ele aponta soluções para sair dessa enrascada, como o paraquedas colorido, ao qual ele se refere nos dois livros. A ideia é a seguinte: já que estamos no processo de perceber que estamos caindo, porque de fato isso já acontece há muito tempo e para muitos povos, devemos criar, então, paraquedas coloridos. Fazê-lo envolve aplicar "toda a nossa capacidade crítica e criativa" (KRENAK, 2019, p. 30) para pensar em alternativas e então vivê-las. As coisas não estão dadas, elas podem ser alteradas, mas qualquer mudança envolveria afeto em relação a toda a vida e uma reavaliação profunda do conceito do "humano". Ademais, podemos chamar aliados para nos auxiliarem na criação de paraquedas. Krenak chama a literatura, a música, os sonhos e a dança, e insiste que o cosmos é infinito; as opções não estão confinadas a um lugar ou a outro e há muita liberdade e riqueza de opções nesse entendimento de mundo.

Os títulos dos ensaios são sugestivos e contêm em si as críticas que Krenak faz à cultura branca, capitalista e ocidental; "Não se come dinheiro", "Sonhos para adiar o fim do mundo", "Máquina de fazer coisas", "O Amanhã não está à venda" e "A vida não é útil" compõem as 116 páginas dessa obra que é central no Brasil para o debate sobre a pandemia, as mudanças climáticas (e, por conseguinte, o Antropoceno) e os efeitos da matriz capitalista nos avanços desenfreados sobre a natureza.

O primeiro ensaio, "Não se come dinheiro", vai direto ao ponto com uma crítica aguda ao problema que se apresenta: quem está no poder não são os governos, e sim as grandes corporações, que, por sua vez, não têm como objetivo o bem-estar social, mas o lucro. E o que é pior, os próprios governos que estão no poder não têm o interesse de assegurar o bem-estar da população ou dos "recursos" naturais das nações; eles são aliados dessas empresas e atuam em favor elas. A construção da natureza na qualidade de dotada de "recursos" é, de fato, grande parte do problema. A Terra não é, em momento algum da equação, vista como um organismo vivo, apenas sendo a matéria prima que serve ao consumo, resultando num entendimento utilitarista da Terra e, consequentemente, em seu esgotamento. 
O progresso é apresentado por Krenak como conceito insidioso, o qual nos leva a acreditar numa narrativa que coloca a tudo e a todos na linha de frente de um projeto que está fadado ao fracasso, e cujo destino físico ou imaginado sequer existe, é apenas "algum lugar". Não só a "Terra" (nos ensaios sempre com letra maiúscula) e seus "recursos" são oferecidos como garantia de que podemos "chegar lá", onde quer que isso seja, mas também, o que Krenak chama de "sub-humanidade", compondo todos os humanos e os não humanos que são tidos como descartáveis e instrumentais para esse fim. Seria Marte esse "algum lugar"? Sobre essa possibilidade o autor pondera, talvez com uma saudável dose de desesperança, dadas as circunstâncias, que o planeta vermelho tornaria-se apenas o novo lar da mediocridade que insistimos em não resolver por aqui, na Terra.

Há, porém, algumas possibilidades para fora dessa mentalidade; há povos e pessoas, denominados povos da Terra, que cultivam "sonhos para adiar o fim do mundo", que é o título do segundo ensaio. Assim como no livro Ideias para adiar o fim do mundo, Krenak retoma a abordagem da relevância do sonho como instituição, como linguagem para entender a si e ao mundo, e como ferramenta para pensar outras formas de viver. $\mathrm{O}$ afeto no sentido de produzir efeitos e nutrir cuidado aparece de maneira central na prática de compartilhar sonhos a qual Krenak foi exposto desde cedo. Você conta o sonho, ele explica, para pessoas próximas:

O que sugere também que o sonho é um lugar de veiculação de afetos. Afetos no vasto sentido da palavra: não falo apenas de sua mãe e seus irmãos, mas também de como o sonho afeta o mundo sensível; de como o ato de contá-los é trazer conexões do mundo dos sonhos para o amanhecer, apresentá-los aos seus convivas e transformar isso, na hora, em matéria intangível (KRENAK, 2020, p. 37-38, grifo no original).

Compartilhar o sonho é, portanto, uma forma de unir forças para construir algo que atravessa o material e o imaterial, além de orientar a ética de convivência entre humanos e não humanos. Krenak conta sobre o sonho que há tempos um pajé compartilhou com ele e com outros da aldeia em que os espíritos da caça e dos animais estavam furiosos. Aquela foi uma comunicação formal de que os avanços do homem branco eram inaceitáveis e estavam a produzir desastres. O sonho é colocado como uma ponte entre humanos e não humanos, um espaço onde é possível estabelecer afetos e comunicações que, por sua vez, formam éticas de viver. A cultura ocidental, porém, dita factual e objetiva, nega o sonho como ferramenta de mudança e propõe construir uma nova Terra em Marte, em vez de abraçar uma compreensão ampla, inclusiva e talvez até curativa de humano.

Krenak destaca que a ousadia do humano ao se pensar especial diante do universo não humano que o cerca é extremamente arriscada. Ele afirma que "os seres humanos não têm certificado, podem dar errado" (2020, p. 41), e chama atenção para o fato de que o entendimento de que o humano é um animal descolado dos outros e do meio ambiente é uma espécie de insanidade. O ser humano que não se alia ao rio, aos animais e à natureza não entende de onde vem e do que depende para sobreviver, e é com clareza que Krenak aponta esses fatos que deveriam ser óbvios. A húbris é tamanha que o novo coronavírus, 
que por enquanto afeta apenas a humanos, não parece ter sido suficiente para nos fazer entender que, de acordo com Krenak, "não somos a humanidade que pensamos ser" (2020, p. 42), ou seja, não há nada de particularmente especial no humano. Se houvesse uma qualidade verdadeiramente singular, "não estaríamos hoje discutindo a indiferença de algumas pessoas em relação à morte e à destruição da base da vida no planeta", argumenta o autor, acrescentando que "[d]estruir a floresta, o rio, destruir as paisagens, assim como ignorar a morte das pessoas, mostra que não há parâmetro de qualidade nenhum na humanidade" (KRENAK, 2020, p. 43). Diante das mudanças climáticas e do que viemos a chamar de Antropoceno, fica evidente que as ações humanas na Terra já produziram efeitos na biosfera a ponto de sermos coletivamente considerados como uma força geológica, além de espécie biológica. O livro de Krenak e a proposta de sonhar alternativas para a matriz capitalista que orienta nossa forma de estar no mundo são valiosos e têm que ser sonhados também nos contextos acadêmicos e fora da academia. "Precisamos evocar", ele adverte, "alguma visão para sairmos desse pântano" (2020, p. 44), e não há tempo a perder. A sexta extinção em massa está em curso, as geleiras estão se esvaindo, as tempestades ficam cada vez mais agressivas e os vulneráveis, humanos e não humanos, ficam cada vez mais vulneráveis.

No terceiro e no quarto ensaio, respectivamente, o autor direciona uma ácida crítica à sociedade consumista e à noção de que o nosso futuro no planeta está garantido. Krenak lembra o leitor de que, enquanto nas histórias de origem ocidentais o humano e o criador sempre estão numa espécie de embate (o dilúvio como uma resposta de Deus para os nossos maus comportamentos, por exemplo), na cosmologia indígena os humanos já foram de tudo um pouco: peixe, árvore e outros bichos e coisas. Nessa compreensão de mundo, todos são parentes e contam com uma rede de apoio que torna a vida possível. $O$ "progresso" que, para ter sucesso tem que instrumentalizar e passar por cima de todos esses parentes, não é cabível nessa forma de conceber o mundo. O ponto central, ou o chaveamento indispensável para enxergar o mundo não como instrumental mas inteiro como vivo, é pensar no que aproxima o humano dos outros animais e da natureza, e não no que nos distingue, que é justamente o aspecto mais frisado. E essa mentalidade, a do excepcionalismo humano, será a que apertará o que o autor denomina como "o botão de nossa autoextinção" (KRENAK, 2020, p. 58). É nesse sentido que vem a sua crítica mais feroz, a de que somos piores que o novo coronavírus, somos "a praga que veio devorar o mundo" (KRENAK, 2020, p. 64). Esta é, ele conclui, a mais temerosa das distopias, já que "em vez de imaginar mundos, a gente os consome" (KRENAK, 2020, p. 69). A Terra, porém, seguirá sem nós, e talvez seja essa a prova cabal da ficção do excepcionalismo humano. Krenak nos provoca a não pagar para ver esse cenário se concretizar.

A pandemia do novo coronavírus se apresenta na fala de Krenak como uma oportunidade de pausa e escuta, como um momento oportuno para repensar o excepcionalismo e as práticas humanas. Quando, antes da pandemia, engenheiros lhe perguntaram de que forma poderiam recuperar o rio Doce, Krenak propôs algo que à época 
pareceu impossível: conter toda atividade humana que incorresse no rio. Mas, eventualmente, em 2020, as coisas pararam de um jeito ou de outro. Certamente não o necessário para evitar, até agosto do mesmo ano, mais de 115 mil mortes apenas no território brasileiro, mas desaceleraram em fases. Parar, que em dado momento apresentou-se como opção impensável, aconteceu. É a Terra querendo cortar o nosso oxigênio, diz Krenak, nos "desligar" (2020, p. 83) ou, no mínimo, nos silenciar um pouco. A imagem que o autor propõe da Terra sendo uma mãe que pede ao filho para ficar quieto por um instante pode fazer com que o feminismo ocidental torça o nariz para a construção, que é uma amplamente utilizada para equacionar mulher e natureza como objetos passíveis de instrumentalização, passividade e violência. É preciso dar um passo para trás e enxergar a imagem a partir da cosmologia indígena, que não é e talvez não devesse ser compreendida por meio das lentes teóricas ocidentais. Esse deslocamento epistemológico parece tanto uma necessidade para o momento quanto um convite que Krenak faz para migrarmos de uma mentalidade hierárquica, que enaltece (certos) humanos, para uma percepção de mundo que nos aproxima de não humanos. Essa qualidade de olhar não permite a declaração insensata de que "alguns vão morrer" em prol da saúde econômica deste ou de qualquer outro país. Não há espaço para o descarte ou sacrifício de idosos, que na cosmologia indígena são tidos como bibliotecas vivas, e na cultura ocidental muitas vezes como um peso ou um ser que não mais contribui para a dita saúde da economia. $O$ importante, destaca o autor, é não buscarmos a normalidade que pensávamos ter antes da pandemia, com a farsa da sustentabilidade que é apenas um selo para aplacar culpas vinculadas ao consumo. É imprescindível aproveitar esse breve e incômodo silêncio para ativar os sonhos e mudar.

Um passo necessário para uma transformação na forma de estar no mundo, para sonhar outros mundos, é reaprender o que estamos fazendo aqui. Da perspectiva do "progresso", um passo que elevasse os grupos de pessoas que, nas palavras do autor, "não estão engajadas no consumo planetário" (KRENAK, 2020, p. 73) poderia parecer como um passo para trás. Isso assim pareceria, porque os processos "civilizatórios", tão violentos e aniquiladores de mundos, tiveram que construir e buscar estabilizar uma narrativa que entendesse esses povos como retrógrados. Krenak argumenta que essas pessoas que não vivem de consumir, de comer a Terra são "a cura para a febre do planeta" (2020, p. 73), e poderiam "nos contagiar positivamente com uma percepção diferente da vida" (2020, p. 73). Essa opção soa por vezes impossível, dada a aparente solidez do mundo como está, mas Krenak relembra-nos de que tudo está em constante mudança e aí mora a oportunidade.

O convite de Krenak para repensar o nosso entendimento de humanidade é mais que oportuno: imaginar mundos é indispensável para que a vida, nossa e de incontáveis seres humanos e não humanos, continue sendo possível e, talvez, melhor. O autor postula que "[o]s outros seres são junto conosco, e a recriação do mundo é um evento possível o tempo inteiro" (KRENAK, 2020, p. 71, grifo no original). Este argumento ressoa com o de pensadoras que as humanidades apreciam e utilizam no ato de pensar o mundo e 
desenvolver teorias, como Donna Haraway, que faz uma crítica cabal ao excepcionalismo humano (2008) e postula que a única forma de estar no mundo nesse momento de disrupção é estar junto com outros ou nada feito. Isso envolve estar profundamente ciente da infinidade de tipos de vidas humanas e não humanas que atravessam a todos e o tempo todo (2016). Há também o trabalho de Joanna Latimer, que ao pensar a relação entre humanos e não humanos desenvolve a noção de "ficar ao lado de" (2013), que de certa forma é o que Krenak sugere quando diz que deveríamos focar no que nos aproxima do mundo não humano e não no que nos distingue dele; e existe ainda a teoria de transcorporealidade, de Stacy Alaimo (2017, publicada pela primeira vez em 2007), que compreende o humano como indistinguível da natureza ou do mundo não humano. Krenak soma a esse rico rol de possibilidades teóricas e lança mão, assim como essas pensadoras, da arte para criar paraquedas coloridos, pensar mundos e ponderar uma vida nutrida de companhias humanas e não humanos. Poesias de Drummond e músicas de Milton ou de Caetano são algumas das referências que aparecem no livro. A arte e a literatura, particularmente, têm como norte a criação de histórias e mundos, constituindo um terreno fértil para testar a pergunta "e se?". Nesse sentido, a obra de Krenak se apresenta como uma contundente metodologia de pensamento crítico para as humanidades e para os estudos literários em especial.

No último ensaio, que dá nome ao livro, Krenak deixa um alerta: é imperativo que as nossas pegadas fiquem mais leves. O autor faz uma crítica social de que precisamos agora, e com a urgência que as mudanças climáticas e seus impactos sociais evidenciam. A ecologia, argumenta Krenak, "nasceu da preocupação com o fato de que o que buscamos na natureza é finito, mas o nosso desejo é infinito, e, se o nosso desejo não tem limite, então vamos comer este planeta todo" (2020, p. 97). O cenário é sombrio. Este mundo que podemos tentar recuperar já acabou para inúmeras pessoas, populações e nações humanas e não humanas -, mas é preciso ressaltar uma característica indispensável da vida: ela "é fruição, é uma dança, só que é uma dança cósmica, e a gente quer reduzi-la a uma coreografia ridícula e utilitária" (KRENAK, 2020, p. 108). Essa colocação dialoga com o fato de que temos que superar a ideia de que a única forma de atingir essa fruição seja por meio do consumo, dos "brinquedos" tecnológicos, como ele assim coloca, que estão comendo o planeta. Encontrar, nas obras literárias, formas de estar no mundo que desafiam essa lógica e descortinam mais semelhanças entre o humano e o não humano do que diferenças, é um dos objetivos da análise literária de viés ambientalista. A obra de Krenak se coloca como um sonho para "pensar junto" e achar caminhos para fora desse cenário que, como ele demonstra, não está dado. O trabalho é complexo, mas o que dá início a ele, o sonho, é simples e acessível a todos: e se?

\section{Referências}

ALAIMO, Stacy. Feminismos transcorpóreos e o espaço ético da natureza. Revista Estudos Feministas. Florianópolis, v. 25, n. 2, p. 909-934, maio-ago. 2017. 
HARAWAY, Donna J. Otherwordly conversations, Terran Topics, Local Terms. In: ALAIMO, Stacy; HEKMAN, Susan. (Eds.). Material Feminisms. Bloomington \& Indianapolis: Indiana University Press, 2008, p. 157-187.

HARAWAY, Donna J. Staying with the Trouble: Making Kin in the Chthulucene. Carolina do Norte: Duke UP, 2016.

KRENAK, Ailton. Ideias para adiar o fim do mundo. São Paulo: Companhia das Letras, 2019.

KRENAK, Ailton. A vida não é útil. São Paulo: Companhia das Letras, 2020.

LATIMER, Joanna. Being Alongside: Rethinking Relations amongst Different Kinds. Theory, Culture \& Society, v. 30, p. 30-77, out. 2013.

\section{NOTAS DE AUTORIA}

Melina Pereira Savi (melsavi@gmail.com) é doutora em estudos literários e conduz pesquisa na área de literaturas ambientalistas e ecocrítica como pesquisadora PNPD no Programa de Pós-Graduação em Inglês da Universidade Federal de Santa Catarina. A pesquisadora leciona, desde 2018, como professora voluntária no mesmo programa e também no curso de graduação em Letras-Inglês do DLLE.

\section{Como citar esse artigo de acordo com as normas da ABNT}

SAVI, Melina Pereira. Para Ailton Krenak em A vida não é útil, "somos a praga do planeta", mas podemos mudar. Anuário de Literatura, Florianópolis, v. 26, p. 01-07, 2021.

\section{Contribuição de autoria}

Não se aplica.

\section{Financiamento}

O presente trabalho foi realizado com apoio da Coordenação de Aperfeiçoamento de Pessoal de Nível Superior - Brasil (CAPES) - Código de Financiamento 001.

\section{Consentimento de uso de imagem}

Não se aplica.

\section{Aprovação de comitê de ética em pesquisa}

Não se aplica.

\section{Conflito de interesses}

Não se aplica.

\section{Licença de uso}

Os/as autores/as cedem à Revista Anuário de Literatura os direitos exclusivos de primeira publicação, com o trabalho simultaneamente licenciado sob a Licença Creative Commons Attribution (CC BY) 4.0 International. Estra licença permite que terceiros remixem, adaptem e criem a partir do trabalho publicado, atribuindo 0 devido crédito de autoria e publicação inicial neste periódico. Os autores têm autorização para assumir contratos adicionais separadamente, para distribuição não exclusiva da versão do trabalho publicada neste periódico (ex.: publicar em repositório institucional, em site pessoal, publicar uma tradução, ou como capítulo de livro), com reconhecimento de autoria e publicação inicial neste periódico.

\section{Publisher}

Universidade Federal de Santa Catarina. Programa de Pós-graduação em Literatura. Publicação no Portal de Periódicos UFSC. As ideias expressadas neste artigo são de responsabilidade de seus/suas autores/as, não representando, necessariamente, a opinião dos/as editores/as ou da universidade.

Histórico

Recebido em: 30/08/2020 
Aprovado em: 05/10/2020

Publicado em: 23/04/2021 